\title{
Chemical Technology at the Imperial College of Science, London
}

$\mathrm{O}^{\mathrm{N}}$ January 16, at the invitation of the governing body and the rector, a distinguished company visited the Department of Chemical Technology of the Imperial College of Science and Technology, the occasion providing an opportunity for observing the progress achieved during the past quinquennium.

Under the leadership of Prof. W. A. Bone, the Department, which is exclusively of a postgraduate and research character, has continued its policy of pursuing investigations of a fundamental and pioneering character bearing upon what may be termed 'long distance' problems of industry. Such work invariably calls for new experimental methods, and a feature of the various apparatus on view was that much of it has been designed in the Department itself and some is unique.

The maintenance costs of the Department's extensive research work are naturally heavy, but the support which has always been forthcoming from outside firms and institutions bears ample testimony to the high regard in which its activities are held. The chief extramural contributors towards the researches have been the Royal Society (Messel Fund), the Department of Scientific and Industrial Research, the British Iron and Steel Federation, Imperial Chemical Industries Ltd., the Gas Light and Coke Company, the South Metropolitan Gas Company, Messrs. Radiation Ltd., Messrs. Ferranti Ltd., Messrs. Westinghouse Brake and Saxby Signal Co., and Messrs. E. G. Acheson Ltd. Altogether, the cost of the research work now amounts to upwards of $£ 9,500$ a year, of which approximately 65 per cent is met by special ad hoc extramural subscriptions. Since its inauguration in 1912, contributions from outside sources towards the research equipment and work of the Department have amounted to more than $£ 60,000$ (capital equipment $=£ 15,000$ ), above five-sixths of which has come through Prof. Bone.

During the afternoon, Prof. Bone gave an account of the work of the Department. In subsequent speeches Prof. H. E. Armstrong and Mr. H. James Yates, chairman of Radiation Ltd., paid a high tribute to it and stressed its scientific and national importance. Although Prof. Bone will shortly reach the retiring age of sixty-five, they think it would be calamitous if a stringent application of a rule were allowed to interfere with its continuity or with his continued direction of it.

Recent advances in the work of the Department, which is divided into sections devoted to fuel technology (including high-pressure gas reactions), electrochemistry and chemical engineering were demon strated in the various laboratories, and may be summarised as follows :-

\section{FUel TeChNology}

Chemistry of Coal. The cost of this work, directed to problems connected with the natural maturing of coal, has been defrayed mainly by grants from the Fuel Research Board. It has resulted in (i) new knowledge bearing upon the origin and development of the main 'coking constituents' of bituminous coals ; (ii) the discovery not only of the essential 'benzenoid' structure of the main coal substance but also the development thereof throughout the ligninpeat-lignite-coal-anthracite series.

Mechanism of Gaseous Combustion. Several investigations have been continued on (i) the combustion of carbonic oxide, (ii) the combustion of hydrocarbons, (iii) flame spectra, etc. New evidence has been forthcoming that carbon monoxide burns in two ways, one involving and the other independent of the intervention of steam; also that the initial oxidation product of a gaseous hydrocarbon is the corresponding alcohol as postulated in the hydroxylation theory.

High-Pressure Gas Reactions and Explosions. The work upon gaseous explosions with which Drs. D. M. Newitt and D. T. A. Townend have been specially associated has been extended to initial pressures of 1,000 atmospheres, the highest yet attempted. Nitrogen activation in explosions of carbon monoxide air media has been shown to reach a maximum at c. 350 atmospheres, and nearly 6 per cent of nitric oxide to be recoverable from $2 \mathrm{CO}+3 \mathrm{O}_{2}+2 \mathrm{~N}_{2}$ explosions at 75 atmospheres.

Dr. Newitt has also developed a new line of work on the pressure oxidation of typical hydrocarbons with the view of elucidating the mechanism of the process and of obtaining large yields of intermediate products. A yield of 50 per cent of methyl alcohol has been obtained from methane and 60 per cent of ethyl alcohol from ethane, while toluene has yielded large amounts of benzyl alcohol and benzaldehyde.

The high-pressure field has also been extended by Dr. Townend to the determination of ignition tem. peratures of paraffin hydrocarbon, etc. - air mixtures, with results of great significance both theoretically and in regard to internal combustion problems. Briefly, it has been discovered that the ignition temperatures are located in two widely separated ranges, one usually above $500^{\circ} \mathrm{C}$. for low pressures and the other below $350^{\circ} \mathrm{C}$. for high pressures. Transference of an ignition temperature to the lower range occurs abruptly at a definite critical pressure ; this pressure corresponds with the incidence of ' $k$ nock' in an engine at a definite compression ratio.

Another centre of interest was an impressive highpressure apparatus designed by Dr. Newitt for investigations on liquid organic reactions at pressures of 5,000 atmospheres. This work, which has been financed by Imperial Chemical Industries Ltd., and is under the joint supervision of Profs. Bone and Thorpe, has met with such success that new installations are now in course of erection for pressures between 10,000 and 20,000 atmospheres.

Flame Propagation in Gaseous Explosions. This work has consisted mainly of photographic researches, throughout which Mr. R. P. Fraser has collaborated with Prof. Bone and developed the present Fraser high-speed camera of the rotating mirror type whereby detailed records are obtained, capable of measuring flame movements of frequency down to one-millionth of a second. Important new knowledge concerning the influence of compression waves, the phenomena associated with 'spin' in detonation and the influence thereon of magnetic and electric fields has been obtained, with the result that a new conception of detonation has been arrived at and is shortly to be published.

Blast Furnace Reactions. Begun in 1925, under the auspices of the British Iron and Steel Federation, this investigation has also made notable advances, special apparatus having been devised for determining the relative velocities of 'carbon deposition' and 'ore 
reduction' reactions at various temperatures and high gas speeds as met with in blast furnace operations. During the past few years the work, which is carried out by Dr. H. L. Saunders, has thrown such important new light on blast furnace reactions that recently the Federation decided to finance and develop parallel investigations upon actual blast furnace plant. With this end in view, a Committee has been formed, with Prof. Bone as chairman, to organise and carry out this programme of work.

\section{EleCtrochemistry}

Gaseous Combustion in Electric Discharges and Electrical Ignition. Inaugurated in 1925 by Asst. Prof. G. I. Finch, these investigations have been continuously prosecuted, and new light thrown on the combus. tion of hydrogen and carbon monoxide and on the part played by the hydroxyl radical in such circumstances.

In addition to having established the excitation view of electrical ignition, a notable improvement in the design of electrical ignition systems for mobile internal combustion engines hasbeenachieved.

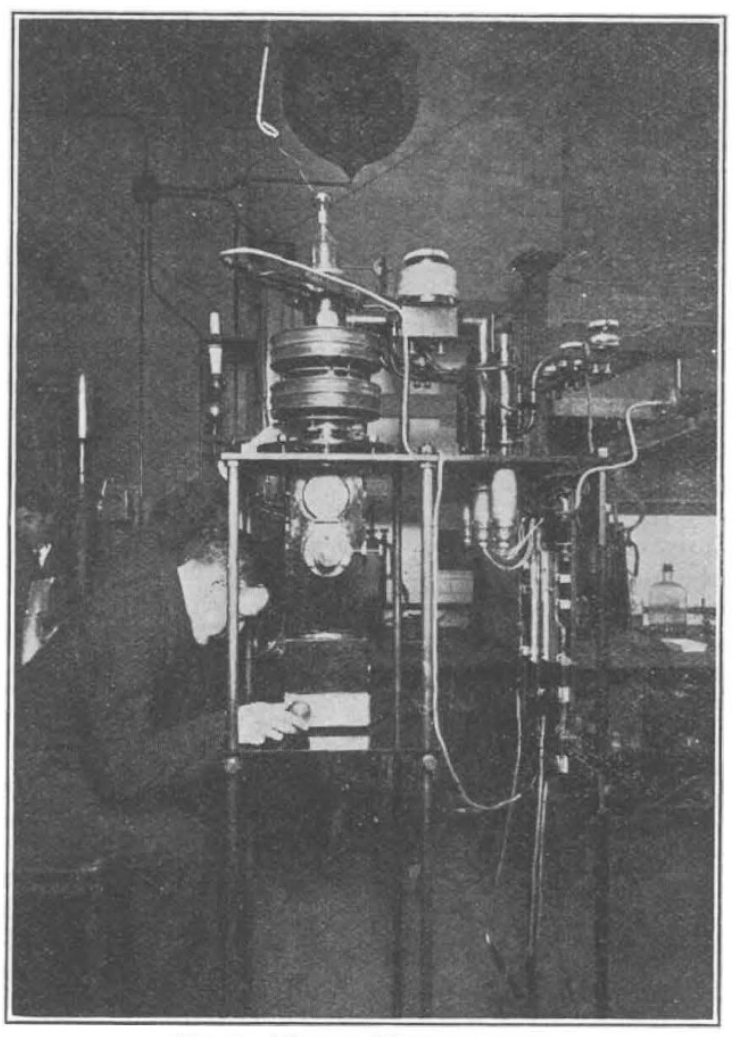

FIG. 1. Electron diffraction camera. has been established that electrical condition, catalytic activity and structure of surface catalysts are intimately related. Great progress in this field has recently been made possible by the application of the electron diffraction method of structure analysis.

A number of precision cameras designed by Prof. Finch were on view (Fig. 1) ; other chemical problems being attacked by this new method are: (i) corrosion, (ii) electrodeposition, (iii) thermionic and photo-electric emission, (iv) lubrication, (v) properties of colloidal metals, (vi) formation of surface compounds, etc.

Chemical Engineering

The chemical engineering section of the Depart ment suffered a severe loss through the death of Prof. J. W. Hinchley in 1931. Since that time, Asst. Prof. S. G. M. Ure has taken charge of it and is directing work on general problems such as : (i) heat transmission, (ii) flow of liquids through granular beds, woven materials, etc., (iii) the distribution of energy in ball mill operations, etc.

During the quinquen. Also as an outcome of work on the analysis of discharge phenomena in ignition, a type of high-speed cathode ray oscillograph has been developed which has now been widely adopted in other laboratories.

Electron Diffraction and Heterogeneous Catalysis. It

nium, 98 students, 21 of them from overseas, have passed through the Department; of 78 whose locations are known, 63 have passed into industry, 10 into research or business posts and 5 into academic work.

\section{Lunar Influence on the East Anglian Herring Fishery}

$\mathrm{F}^{\mathrm{L}}$ LUCTUATION in the yield from year to year, from month to month, and even from day to day, is one of the outstanding and disconcerting characteristies of all herring fisheries. For thirteen seasons, 1921-1933 inclusive, careful records have been kept of the amount of herrings landed daily at Yarmouth and Lowestoft during the late autumn (October-November) fishery off the East Anglian coast. These figures of daily landings have now been submitted to detailed analysis by the scientific staff of the Ministry of Agriculture and Fisheries, Lowestoft, who find that they reveal a definite monthly rhythm in the catches, the maxima coinciding with the period of full moon*.

When the moon is at full in the first week of October its effect is but slight, but the landings gradually increase as the season advances, to culminate in a peak during the week of November full

* Lunar Influence on the East Anglian Herring Fishery. By R. E. Savage and W. C. Hodgson. Journal du Conseil, 9, No. 2, 1934 ; pp. 223-239. moon. In these circumstances, it is only the middle and later parts of the season which produce good catches. A full moon occurring in the second week of October produces a pronounced peak in the curve of landings, this maximum being followed by one of approximately equal magnitude in the week of November full moon. Full moon in the third week of October produces a still more pronounced peak for this period, but the corresponding November full moon is considerably less effective. Finally, when the moon is at full during the fourth week of October, it produces the largest peak of all, but the late November moon is accompanied by a rise so slight as to be of little benefit to the fishery.

From these observations it follows that the best prospects for a successful fishery - at any rate from the point of view of production-are found when the October full moon occurs in the second week of the month. When this happens, the combined effects of the October and November moons are greatest, and a period of about five weeks good fishing may bo 